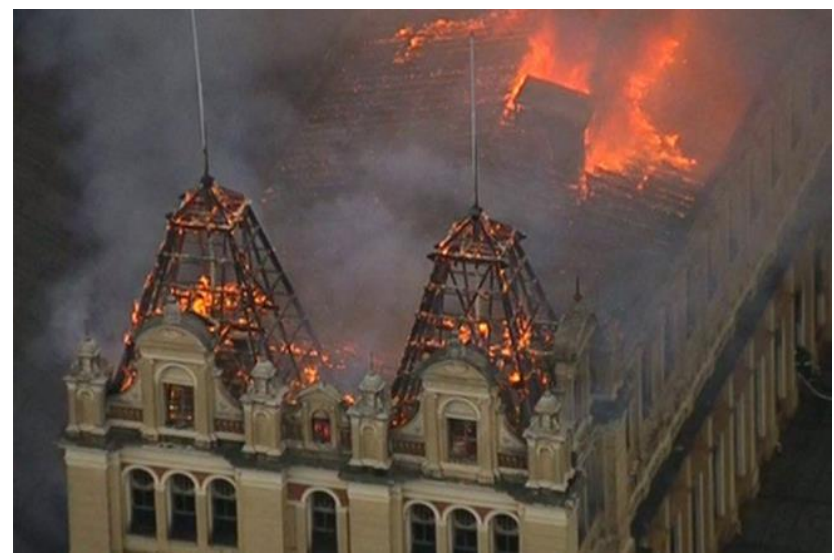

\title{
Documentário, língua e o museu no/pelo olhar discursivo
}

Documentary, language and museum in/by the discursive look

\author{
Maria Cleci Venturini ${ }^{1}$ \\ https://orcid.org/0000-0002-5576-2745 \\ Suhaila Mehannan Schon ${ }^{2}$ \\ https://orcid.org/0000-0002-9352-4852
}

\begin{abstract}
Resumo:
Nossa proposta, com esse texto, é discutir a história e a memória em relação ao museu e a língua no/do museu e da vida. A delimitação constitutiva dos dispositivos analíticos é o documentário "A chama da língua" em que vozes aparentemente desencontradas falam de língua e de museu. Dentre essas vozes há uma que discute, analisa e organiza as 'vozes' de pesquisadores que colocam em suspenso a língua no museu, destacando que a 'língua que nos une é a língua que nos diferencia'. Diante dessa "voz" perguntamos: Como a língua sempre em movimento e em transformação pode estar no museu e como se naturaliza e se legitima a língua no museu? As discussões que sustentam as análises incidem sobre documentário, museu e língua e atendem aos pressupostos teóricos da Análise de Discurso, centrada em Pêcheux e em campos disciplinares que contribuem para o entendimento dos museus e das temporalidades em funcionamento nesse lugar institucional, como lugar de memória.
\end{abstract}

Palavras-chave: língua, história, memória, discurso, museu.

Abstract:

Our proposal with this text is to discuss the history and memory in relation to the museum and language in/of the museum and of life. The constitutive delimitation of the analytical devices is the documentar "A chama da língua" (The flame of the language, freely translated to English) in which voices seemingly mismatched speak of language and museum. Among these voices there is one that discusses, analyzes and organizes the 'voices' of researchers who put the language in suspense in the museum, emphasizing that the 'language that unites us is the language that sets us apart'. In front of this "voice" we ask: How is the language always in movement and in transformation can be in the museum and how is the language naturalized and legitimized in the museum? The discussions that support the analyzes focus on documentary, the museum and language and attend to the theoretical assumptions of Discourse Analysis, which focuses on Pêcheux and in disciplinary fields which contribute to the understanding of the museums and the temporaries operating in this institutional place, as a place of memory.

Keywords: language, history, memory, discourse, museum

\footnotetext{
${ }^{1}$ Professora associada da Universidade Estadual do Centro-Oeste do Paraná, vinculada ao Departamento de Letras e ao Programa de Pós-graduação em Letras. Realiza Estágio Sênior sob a supervisão do Prof ${ }^{\circ}$ Dr. Fernando Catroga, na Universidade de Coimbra (fevereiro de 2017 a janeiro de 2018) com bolsa Capes, processo BEX 0460/16-3, acordo Araucária/Capes, edital 017/2015. E-mail: mariacleciventurini@gmail.com.

${ }^{2}$ Mestranda em Letras, Programa de Pós-graduação em Letras, da UNICENTRO, Campus Santa Cruz.

Professora da Rede Pública Estadual do Paraná. E-mail: suhailaschon@ gmail.com
} 
[...] Saussure não resolve a contradição, invisível antes dele, que une a língua à alíngua: ele a abre, tornando-a visível. Se o diurno não suporta ser separado do noturno, o estatuto do conceito é desviado na sua relação com os deslizamentos da metáfora e do equívoco. A ausência de um conceito não produz seu simples contrário, e a loucura não é a sua simples mudança ou falta. É na trama imaginária de uma teoria que se negocia a relação com a loucura: quando, hoje em dia, decidimos lançar a ciência contra a loucura, começamos a fazer da ciência uma lógica oposta à não-lógica da loucura; esquecemos, assim, que a loucura (e a poesia) fazem também um certo uso da língua, são igualmente apreendidas no real. A língua como lugar de um saber em que ficções podem ser regradas é o ponto logofílico contraditório pelo qual a linguística toca o seu real. (GADET e PÊCHEUX, 2004, p. 63)

\section{A língua e museu: questões e afirmações}

A epígrafe com que iniciamos esse texto dá a dimensão da contradição estabelecida entre língua e museu, especialmente, quando se concebe o museu como lugar de memória, que atua na manutenção do que precisa/deve ser salvaguardado do esquecimento ou se encontra perigosamente à margem das práticas sociais constitutivas da formação social. Os lugares de memória sinalizam para a necessidade de as memórias serem protegidas/mostradas/preservadas para continuarem a existir e a instaurar efeitos de sentidos. A concepção de museu mais corrente é a de espaços ligados ao já-vivido e ao já significado, relacionadas, segundo Catroga (1998, p. 20), à ordem do saber, em que ressoa a organização e a catalogação. Essa definição de museu e da língua nele é que motiva as discussões propostas nesse espaço e no documentário que nos propomos a analisar.

A nossa filiação à Análise de Discurso, como disciplina de interpretação, demanda desnaturalizar o sentido fechado e saturado de Museu, especialmente, o 'museu da língua'. A ancoragem para essa desnaturalização vem dos questionamentos realizados por pesquisadores que 'falam' no documentário 'A chama da língua', e reiteradamente perguntam se 'a língua tem museu?' Além do questionamento, faz eco a afirmação: 'a língua que nos une é a língua que nos diferencia', podendo-se sustentar por esses enunciados o ressoar das teses de doutorado de José Simão Silva Sobrinho (2011) e de Larissa Montagner Cervo (2012) que a partir da língua imaginária e fluída (ORLANDI, 2003) veem a possibilidade de refletir a prática teórica de língua fluída e imaginária instaurando redes parafrásticas com o enunciado 'a língua é o que nos une’3, com a língua como patrimônio imaterial e a afirmação de Baldini (2013), em texto publicado na Revista Letras, UFSM, asseverando que 'o que une é aquilo que nos

\footnotetext{
${ }^{3}$ Parte do título de sua tese defendida, em 2011, na Unicamp, sob a orientação de EniOrlandi e também slogan do Museu de Língua Portuguesa.
} 
separa' e que também constitui rede com o enunciado 'A língua que nos une é a que nos diferencia'.

Pelos enunciados de Silva Sobrinho (2011), de Baldini (2013) e as discussões de Cervo em torno da língua como patrimônio imaterial os sentidos de museus ressoam discursos sobre a língua e o funcionamento de um discurso de, como uma memória que ancora e sustenta o discurso em circulação no museu e sobre ${ }^{4}$ o museu. Esse discurso de, instaura redes parafrásticas na significação da língua, como aquela que nos une $\mathrm{e}$ que nos separa e com a que nos une e nos diferencia. $\mathrm{O}$ documentário 'A chama da língua', parte do documentário maior 'A Língua tem Museu', E-ladis USP, Ribeirão Preto, inscreve-se no projeto 'Museu vivo da Língua Portuguesa', coordenado por Lucília Maria Abrahão Sousa e nele, a questão 'A língua tem museu?' e a afirmação 'A língua que nos une é a língua que nos diferencia' instauram a coerência dentro da incoerência das falas aparentemente desencontradas que dão visibilidade à contradição do que é, mas também do que não é, a língua na construção da diferença, a língua como 'não todo', de que fala Milner (1987) e a língua entre dois 'reais': o da língua e o da história, preconizados por Gadet e Pêcheux (2004).

Na perspectiva discursiva, os 'saberes' sobre o museu vem de outros lugares e de outros domínios, destacando-se o da história, o da antropologia, o da museologia e o da arquivologia, podendo-se dizer, que é um lugar de memória, ponto nodal para o trabalho realizado por Venturini (2017) no projeto "Museus, arquivos: lugares de memória no/do espaço urbano". Venturini (2009, p. 40) desloca a noção lugar de memória, de Pierre Nora (1992), tendo em vista o funcionamento da AD no entremeio de disciplinas e de saberes, significando o lugar de memória "como dispositivo que organiza a repetição [...] e também os esquecimentos, entre a língua e a história que se realiza no encontro de uma memória e uma atualidade, constituindo o acontecimento". Demanda, desse posicionamento, mobilizar os funcionamentos e domínios de memória em torno do museu, mais especificamente, do museu da língua, com vistas a verificar os espaços de memória que o acontecimento museológico convoca e reorganiza o discurso sobre a língua e os saberes que fazem dela uma língua portuguesa ou brasileira.

O deslocamento a que nos referimos, nesse texto, é determinado pelo museu, definido como o lugar do 'já vivido' e do 'já significado', submetido a instituições,

\footnotetext{
4 O discurso de (memória) e o discurso sobre (atualidade) referem ao funcionamento da memória, trabalhados por Venturini (2009, 2015), sustentando que a memória ancora o discurso sobre, no discurso em circulação, fazendo sentido.
} 
responsáveis pelo 'gerenciamento' e pela interpretação/significação do objeto histórico. O funcionamento desse espaço como lugar, que por ser nomeado de museu da língua, "guardaria" a língua como patrimônio, é que nos permite colocar em suspenso o museu como lugar que gerencia o passado a partir de horizontes de expectativas que determinam as versões do que o museu 'guarda' ou 'dá a ver'. O questionamento ancora-se no museu como espaço em que o tempo tridimensional, segundo Catroga (1998, 2001, 2009), desdobra-se no presente-presente, no presente-passado e no presente-futuro, constituindo efeitos, especialmente, na perspectiva discursiva, a partir do 'olhar' do analista e de como ele pratica a alteridade. Assim, resumimos e definimos o museu como espaço discursivo, pensando a noção espaço discursivo à luz de Pêcheux (2002) como o lugar do enunciável, que possibilita que um enunciado derive para outro enunciado e, também, referida por Courtine (1981) como domínio de memória, possibilitando a apreensão dos funcionamentos discursivos. Esses espaços discursivos, conforme destacou Venturini (2009, p. 49) organiza as redes de memórias e os discursos transversos, mais especificamente, a memória e a exterioridade que instauram discursividades e produzem efeitos parafrásticos.

No documentário, constituem-se alguns simulacros - no sentido de simulacro tratado por Baudrillard $(1991)^{5}$ - dentre eles, o de que a voz de pesquisadores conhecidos são vozes anônimas, dando corporeidade à fala sobre a língua e a relação língua/museu, a partir de diferentes posições-sujeitos. Essas posições interferem na concepção de língua, tendo em vista as correntes linguísticas que sustentam/ancoram os campos disciplinares aos quais os pesquisadores se filiam e, consequentemente, a concepção de língua. Outro simulacro que pode estar em funcionamento no documentário é que os sujeitos que falam 'filiam-se' a distintas teorias pelo efeito que as questões colocadas instauram.

Esses simulacros podem funcionar como mecanismos constitutivos das filiações dos sujeitos e de suas vozes, uma delas, a que ressoa como dissonante, pois questiona a língua no museu, apresenta ponderações e coloca em suspenso a língua nesse lugar, com destaque para, se ele 'guarda' uma língua, vale perguntar que língua é essa. Essa voz dissonante é o fio condutor das nossas reflexões e, a partir dela, perguntamos pela língua que esteve/está no museu e sublinhamos a língua constituída por um real que é da

\footnotetext{
${ }^{5} \mathrm{O}$ simulacro recobre, de acordo com Baudrillard (1991), a construção de efeitos de verdade, de tal modo que um acontecimento mesmo que inventado, passa a ser tomado como verdade, o que impossibilita a separação entre o que é da ordem da realidade e o que não é.
} 
língua e por um real que é da história e que abre para o simbólico, para sentidos outros, para transformações, para movimentos. Pensamos, também, a partir de Pêcheux (1997), na língua funcionando por meio de uma base linguística e por processos discursivos, mostrando a língua em sua opacidade.

Parte dessa opacidade decorre dos sentidos das palavras, as quais, segundo Pêcheux (1997, p. 161), não existem na literalidade do significante, ao contrário, elas são determinados "pelas posições ideológicas que estão em jogo no processo sócio histórico, no qual as palavras, expressões, proposições são produzidas (isto é, reproduzidas)". Isso significa que os sentidos dependem de sujeitos, das posições e dos lugares institucionais e sociais em que eles se inscrevem. Diante da língua relacionada/dependente de sujeitos, de condições de produção, de temporalidades e de espaços sociais e discursivos, a questão que nos mobiliza e impulsiona é: Como a língua sempre em movimento e em transformação pode estar no museu e como se naturaliza e se legitima a língua no museu?

Como se trata de um documentário, após as primeiras palavras, buscamos abarcar essa textualidade, centrando-nos na 'Chama da língua' e no Museu de Língua Portuguesa, significando o museu como lugar de memória, tal como trabalhado por Venturini (2009, 2017). Designamos esse espaço analítico de condições de produção, tendo em conta que por elas é possível explicitar e dar a 'ver' aos sujeitos a construção imaginária do leitor/interlocutor do objeto discursivo analisado, destacando os recortes e a interpretação decorrente dos dispositivos teórico-metodológicos. Em seguida, entrelaçamos teoria e análises, recortando, como dissemos de início, a voz dissonante que problematiza a língua no museu e o museu da língua.

Vale sinalizar que a voz dissonante sobrepõe-se a outras 'vozes' e, por estar no 'entremeio' precisa ser contraposta ou justaposta a elas. É possível compreender que as vozes - que chamamos de 'outras' - sirvam para sustentar e problematizar a língua no/do museu, referendando e funcionando como ancoragem para o argumento, segundo o qual a língua 'não tem museu'. No 'ruído' e na indefinição, dessas outras 'vozes', que dizem da língua e do museu, instauram-se efeitos de nebulosidade, sinalizando para a indefinição e para a incerteza no que tange à legitimidade ou à capacidade de um museu poder/dever ser da língua ou da 'língua ter museu'. Nas considerações finais, que chamamos de 'efeito de fechamento', retomamos a questão de pesquisa proposta para este texto e sublinhamos a impossibilidade de 'fechar' uma interpretação, ainda mais que na Análise de Discurso, a língua é instauradora da falha e da falta, nunca da certeza. 
Além disso, a língua e a linguagem como processos discursivos não se fecham, ao contrário, abrem-se sempre para o "a mais", para as bordas transbordantes, grávidas de sentidos e de efeitos que convocam o devir.

\section{Os documentários, museus e língua em (sus)penso}

Na Análise de Discurso, disciplina de entremeio, trabalhamos com diferentes textualidades, dentre elas, o documentário como uma modalidade constituída pelo verbal e pelo não verbal, presente em pesquisas discursivas, mas ainda pouco teorizadas, talvez pela filiação às ciências sociais. Assim como as demais textualidades, o documentário faz sentido pelo gesto de interpretação do analista no recorte do objeto de análise e desse recorte estar sempre, de acordo com Orlandi (1999), dependente da questão de pesquisa. A mesma autora destaca que os gestos interpretativos são realizados em consonância com as filiações e os posicionamentos do sujeito que assume a posição de locutor e a responsabilidade de dizer o que diz a partir dessa posiçãosujeito e da memória, que determina o dizer. A Análise de Discurso centra-se nos processos discursivos, no modo 'como' se constituem efeitos de sentidos e na materialidade discursiva.

Assim como as demais textualidades, o documentário não prescinde de sujeitos que assumem a responsabilidade pelo dizer, o qual se realiza, no documentário, pelo tratamento criativo de uma realidade ou de uma virtualidade relacionada a sujeitos e à formação social, a partir de uma prática política. Antes de avançar, vale destacar que o sujeito interpelado pela ideologia e atravessado pelo inconsciente, portanto, dividido, cindido e sempre à frente de toda e qualquer formulação, tem a ilusão de ser a origem do dizer e de que o modo de dizer não pode ser outro ${ }^{6}$. Esse destaque é necessário, tendo em vista que "só há prática através de e sob uma ideologia e só há ideologia pelo sujeito e para sujeitos” (PÊCHEUX, 1997, p. 149). Essas teses são centrais na Análise de Discurso, pois dão sustentabilidade à teoria não-subjetiva da subjetividade e à afirmação de que os discursos são sempre ideológicos e, os sujeitos, apesar da ilusão de liberdade e de originalidade, filiam-se em formações discursivas, que determinam, conforme Pêcheux (1997), o que pode/deve ser dito e, também, o que é apagado pelas evidências que se constituem pelo trabalho da ideologia.

${ }^{6}$ Essas ilusões são tratadas por Pêcheux (1997) e por Orlandi (1999) e outros textos, como esquecimentos da ordem da enunciação (esquecimento $n^{\circ} 02$ ) e da ordem da ideologia (esquecimento $n^{\circ} 01$ ). 
O sujeito, na teoria discursiva, de acordo com Pêcheux (1997, p. 214) desdobra-se em sujeito locutor, responsável pelo conteúdo do dizer e pela versão constitutiva do intradiscurso - eixo da formulação - e o Sujeito (com ' $S$ ' maiúsculo), que representa o chamado "sujeito universal, sujeito da ciência ou que se pretende como tal". Esse sujeito responde pelos saberes, advindos do eixo da constituição - interdiscurso. Pêcheux (idem) destaca que o desdobramento do sujeito tem a ver com a relação entre o pré-construído "e seu sentido sob a forma da universalidade". No documentário, como em todo discurso, há um posicionamento político que se manifesta/significa por sujeitos, sinalizando para a interpelação ideológica e para a inscrição desses sujeitos em formações discursivas. Destacamos, portanto, que na perspectiva discursiva, há sempre um posicionamento político e não uma representação. Segundo Orlandi (2011, p. 53),

O político, tal como o pensamos discursivamente, está presente em
todo discurso. Não há sujeito nem sentido que não seja dividido, não
há forma de estar no discurso sem constituir-se em uma posição-
sujeito e, portanto, inscrever-se em uma ou outra formação discursiva
que, por sua vez, é a projeção da ideologia no dizer. As relações de
poder são simbolizadas e isso é o político. A análise do discurso, por
sua vez, como diz Courtine (1982), trabalha com a textualização do
político.

Nesse sentido, o documentário, segundo Guimarães (2013, p. 33), “é uma materialidade da mídia e, nele, instaura-se a relação entre o fato e a realidade constituindo efeitos de verdade". Essa definição de documentário sublinha a recriação de fatos a partir do lugar de onde o sujeito trata dele e do lugar da mídia na constituição de efeitos, de simulacros. Em sua dissertação, Guimarães (2013) ancorou-se em Orlandi (2011), no destaque à filiação do discurso a posicionamentos políticos por se tratar de escolhas ligadas à ideologia e à filiação dos sujeitos em classes sociais, conforme Pêcheux (1997). O documentário, segundo Orlandi (idem), é um objeto de arte ligado à memória, tendo em vista que discursivamente ele pode transformar-se, instaurando o acontecimento discursivo.

De acordo com Orlandi (2011, p. 55), “o documentário recorta, sem o saber, a memória em algum lugar e tempo, produzindo o acontecimento", e nesse recortar, produz o acontecimento, mas não o representa, ao contrário, constitui efeitos de sentidos em torno dele porque faz trabalhar o político por meio do 'gesto' realizado, a partir de um lugar e de um funcionamento simbólico. Assim, entendemos que no documentário ocorre o trabalho entre significantes que constituem efeitos de realidade pela história 
convocada, como campo do saber compromissado com a veracidade. De acordo com Orlandi, (2011), no documentário a formulação decorre do 'fazer acontecer' uma versão, perpassada pelo efeito metafórico e pela deriva de um acontecimento discursivo,

[...] que faz com que algo apareça como acontecimento. Ele constrói o acontecimento que mostra. E o que mostra é um efeito de presentificação (atualidade) produzido, como disse, pelo jogo do interdiscurso (memória discursiva) e a memória institucional (a de arquivo) postas em contradição. E por este gesto ele produz um passado. (ORLANDI, 2011, p. 56)

É assim que o incêndio do 'Museu de Língua Portuguesa' - um acontecimento é o fio condutor do documentário 'A chama da língua' e, nele, as sirenes, as vozes superpostas e as cinzas constituem efeitos de desencontros e de ruídos decorrentes da ausência da imagem dos sujeitos - só são ouvidas as vozes. Essa organização da materialidade significante instaura evidências de que os sujeitos 'falam' e, aparentemente, decidem o 'como' e o que 'falar' sobre a língua no museu ou sobre o museu da língua, como se coubesse a eles determinar a textualidade, apagando que os saberes influenciam os sujeitos inscritos em formações discursivas que determinam o dizer.

A construção discursiva realiza-se dentro da cidade de São Paulo e inicia com o movimento dos bombeiros, das sirenes e dos ruídos do povo na rua. O prédio do museu em chamas destaca-se e, entre fragmentos de discursos poéticos que tomam a língua como objeto criativo ou como tema, são dados a 'ver' os espaços do museu, destacando depoimentos, declarações e parte do que circulou no lugar. A língua, no museu, constitui-se pela vida presente nele, com crianças correndo, com interações entre sujeitos e diferentes textualizações em discurso, enfim como a língua 'movimento'. A par disso, são dadas a 'ver' as 'cinzas' do museu como resto de algo que foi 'chama' e, talvez, porque é 'chama' possa ser novamente 'fogo', no entanto como cinza, 'parece' ter tido fim. Esse é outro simulacro.

Os sujeitos falam sobre museu, sobre a língua, sobre a língua no museu, sobre a língua no ensino, sobre a língua na literatura, enfim sobre a diversidade do seu funcionamento. Além da voz que chamamos de dissonante, um dos sujeitos situa historicamente o museu e a estação da Luz, no centro de São Paulo, constituindo-se como a voz que dá visibilidade ao lugar onde está o museu, significando a singularidade do lugar não somente no presente, mas também no passado de sua constituição. Essa 
'voz' se relaciona ao museu, mais como prédio e construção, como diz o sujeito que retoma e organiza os dizeres e temos chamado de 'dissonante', pelo lugar de onde fala, pela posição que assume nessa FD, contra-identificando-se à língua no museu e ao museu da língua. Por meio dessas ponderações e de retomadas o museu funciona como 'guardador' de memórias, constituindo-se como o lugar institucional em que determinadas modalidades linguísticas são preservadas e as variantes e as variações sejam vistas como o que faz parte da Língua Portuguesa, mas não se iguala à modalidade de língua considerada legítima no português brasileiro, filiado e dependente do Português de Portugal.

No documentário 'A chama da língua', há discussões sobre 'a língua no museu’ e sobre o 'museu da língua' e ressoa, por meio dessas discussões, o trabalho de Sousa (2011), que trata das "Exposições do Museu da Língua Portuguesa: arquivo e acontecimentos e(m) discursos", aliando teoria e prática, discutindo as exposições temporárias e a organização dessas exposições, dando relevância à literatura, recortando Guimarães Rosa e Clarice Lispector, mas também a língua compreendida como condição de estrutura e deslocamentos. "Escutar o jogo da/na língua, percebê-la não apenas como instrumento a ser usada para um fim utilitário, mas observar a historicidade, a espessura de equívoco e a inscrição do interdiscurso e da ideologia nas palavras [...] (SOUSA, 2011, p. 220).

Desse modo, o documentário 'A chama da língua' constitui redes de sentidos com outros textos que autorizam e legitimam os pesquisadores a afirmarem que 'a língua é o que nos une', a questionarem se 'a língua tem museu', demandando que aquele que chamamos de 'dissonante' afirme que 'a língua que nos une é a que nos diferencia'. As falas sobre a língua e sobre a língua no museu sustentam-se em concepções de língua que ancoram e legitimam o dizer sobre a língua e essas concepções ressoam no 'dizer', sinalizando para a interpelação ideológica e para o atravessamento do inconsciente, que mostra que um estruturalista concebe a língua como sistema de regras, no qual um signo é o que o outro não é, conforme Saussure, do CLG. Nessa concepção, a língua submete-se à gramática e permite significar o museu como o lugar em que os sujeitos podem ver a língua funcionando e, a partir desse funcionamento, entender as suas regras, a sua estrutura. Isto não é dito pelos pesquisadores, mas é um possível sentido do museu e isso, o sujeito que 'organiza o que é dito sobre a língua e sobre o museu da língua, destaca quando assevera que é "uma determinada língua que está no museu” e não ‘a língua'. 
Apesar de o documentário cumprir um roteiro e um planejamento prévio, os sujeitos que falam exercem uma função-autor, simulando espontaneidade e, por essa simulação há no documentário efeitos de agitação, de movimento que se aproxima ao movimento da língua, que é de todos e não é de ninguém, que escapa ao controle à norma, mas contraditoriamente se submete, em parte, porque se constituiu, como já assinalamos, por uma base linguística e processos discursivos. O documentário é uma textualidade em movimento e instaura redes metafóricas em relação à Língua Portuguesa e às contradições decorrentes dessas redes, a começar pelo nome da língua Portuguesa - e mais ainda pela língua que está no museu.

Esses sujeitos são pesquisadores e não desconhecem a língua que está na História das Ideias Linguísticas, nem a das gramáticas e dicionários. Quando um deles diz que as pessoas "não param para pensar na língua, quando falam”, ressoa a recriação de uma das premissas da concepção tradicional de língua em que pensar e falar são equivalentes e consequentes. Esse dizer reforça a relação língua e pensamento em defesa da premissa de que o sujeito 'fala mal' porque 'pensa mal', colocando em suspenso a relevância do pensar sobre a língua como manifestação de linguagem. Segundo Orlandi (1999, p. 34), “ao falarmos nos filiamos a redes de sentidos, mas não aprendemos como fazê-lo, ficando ao sabor da ideologia e do inconsciente." Isso significa que o sujeito constitui-se pelo esquecimento em torno do dizer - do domínio da enunciação e do conteúdo do dizer - do domínio do ideológico e do inconsciente.

O efeito de que cada entrevistado 'sabe' do que está falando, simula a liberdade desses sujeitos e possibilita a realização de questionamentos sobre o acontecimento 'da língua no museu' e, também, do museu da língua. O documentário instaura e mantêm redes discursivas, aglutinando acontecimentos relevantes, quais sejam: o de haver um museu da Língua Portuguesa; o das condições sócio históricas do lugar de funcionamento do museu; a da forma de constituição do museu e o que havia nele e, também, o do incêndio que destruiu o lugar. O fio condutor da textualidade não é a narrativa em torno de um acontecimento, mas em torno de 'falas' aparentemente desencontradas de sujeitos, ressoando a tragédia decorrente da destruição do museu e da possibilidade desse acontecimento afetar a língua como instituição nacional. O incêndio é contado/narrado por meio de falas, de ruídos e de imagens do fogo e esse 'contar' instaura efeito de instabilidade, ressoando uma questão: a língua como estrutura ou sistema teria sofrido as consequências da destruição? A razão da pergunta filia-se ao 
nome do lugar: Museu da Língua Portuguesa. Essa questão não está posta, mas é um dos possíveis efeitos de sentidos.

Antes de iniciar as análises e de discutir a língua e os museus, vale destacar que o documentário "A chama da língua" constitui-se de versões e de histórias, sustentadas pela metáfora do 'fogo' e da 'chama'. Entendendo-se o fogo como o que faz arder e, nesse acontecimento do incêndio, no museu, mostra a destruição de um espaço físico, em que a 'chama' simula a língua viva e em movimento, por meio de redes metafóricas constituídas pela relação entre língua e fogo, sinalizando que a língua 'vive' sob as cinzas e reacende a 'chama'. Esse efeito de sentido sustenta-se por essa rede metafórica, incluindo as cinzas nessa relação e se ancora na memória de que debaixo das 'cinzas' há 'brasas' e, consequentemente 'fogo', fazendo rede com um saber anterior, segundo o qual a língua é o lugar material da ideologia, portanto, do sujeito, segundo Pêcheux (1997). O documentário apresenta sequências de falas-fatos, que se apresentam como 'ruídos' porque são organizadas e postas em discurso pela voz que recortamos como a que se contra-identifica, como quem se distancia e analisa e, dessa distância pode/deve dizer pelo lugar que ocupa. Algumas vozes constituem redes com dizeres que já circularam 'antes' em outros lugares como a 'poesia', em Sousa (2011), a 'língua como patrimônio', em Cervo (2012), a 'língua que nos une', em Sobrinho (2011) e como 'o que nos une é o que nos separa', em Baldini (2013), constituindo redes parafrásticas e o efeito de sobreposição de dizeres, dando visibilidade a filiações teóricas e a posicionamentos políticos e discursivos sobre a língua e sobre o museu da língua.

O museu como lugar de memória e de saberes ligados ao que fez e continua a fazer sentido, abriga - como já destacamos - o vivido filiado e relacionado a uma realidade como "parte do modo de individuação do sujeito capitalista em nossa formação social", conforme Orlandi (2014, p. 2). Da relação sujeito capitalista e sociedade, de acordo com a mesma autora, forma-se o Estado com os sentidos sociais que se apresentam como parte da memória, não de indivíduo, mas de sujeitos que praticam a mesma língua e o que 'fala' antes, sempre como memória, mesmo os sentidos sendo fluidos, assim como o é a língua, de acordo com Milner (1987), enquanto não-todo.

Resumindo, no documentário 'A chama da língua', as redes de memória constituem-se pelas relações 'museu X preservação' e 'museu X passado', sinalizando para recorrências e repetições, referindo ao passado 'olhado/significado' a partir de um presente que encaminha para um futuro. O binômio 'museu x preservação', na 
convocação da língua, instaura contradições e equívocos, tendo em conta que a língua tem um passado. Entretanto, a dificuldade está na delimitação desse passado, pois quando se pensa/fala/convoca a língua emerge o movimento, a impossibilidade de gerenciamento, especialmente do tempo, pois a língua do passado está no presente e certamente estará no devir. A língua não se fecha e não é unívoca. Está sempre sendo ressignificada por pesquisadores que a 'veem' a partir de teorias, as quais lhes permitem defini-la, considerando práticas de sujeitos que a vivenciam, sem necessidade de teorizações, definições ou abstrações. Segundo Pêcheux (1997, p.91),“o sistema da língua é, de fato, o mesmo para o materialista e para o idealista, para o revolucionário e para o reacionário, para aquele que dispõe de um conhecimento dado e para aquele que não dispõe desse conhecimento". Com isso, Pêcheux refere a uma base linguística comum e à realização de processos discursivos distintos, por envolverem processos ideológicos que simulam, dentre outros, o processo científico e sinalizam que não há uma língua para cada classe social. Isso, entretanto, não significa a 'indiferença' das classes sociais em relação à língua quando da sua mobilização e das relações contraditórias decorrentes de processos discursivos na constituição de efeitos, como evidências constituídas pela ideologia, simulando concretude e fechamentos, aparentemente, legitimados por tecnologias como a gramática e os dicionários.

\section{A língua no museu e a voz dissonante entre 'chama' e língua}

"A chama da língua" aborda acontecimentos filiados à formação social e trata-os de modo criativo, mobilizando funcionamentos e redes metafóricas, parafrásticas e de sentidos polissêmicos para as mesmas palavras, dispostas em texto, que significam a partir de lugares, de posições-sujeito e de saberes e dizeres assumidos por sujeitos e em relação às condições de produção do discurso.

O documentário, em análise, inicia-se com vozes aparentemente sobrepostas, pelas quais ressoam outros dizeres e saberes já-ditos e significados antes em outros lugares como pré-construídos. São apenas dizeres em rede, aparentemente sem ligação. Continua com a chama, depois o escuro e o barulho da sirene, seguindo-se as chamas no prédio, o título do documentário. Novamente as sirenes, uma placa com os dizeres 'espaço estação' - sirenes, portas interditadas e a escrita 'Defesa Civil- PMSP'. Esse primeiro quadro se fecha com a definição de tragédia e com as cinzas, que significam pelo que não estão nelas, mas ressoam por outros discursos e pelas memórias em torno 
da cinza e do fogo, da destruição e do que está debaixo das cinzas. Com isso, no nosso entendimento, se fecha uma primeira parte do documentário e nela se evidencia a destruição, a tragédia decorrente do incêndio no museu e, por extensão, da língua. Essa primeira parte constitui efeitos bastante interessantes, pois se "a língua está no museu" e o "museu é da língua", com o fogo e com a tragédia tudo estaria 'consumado', ressoando aqui um discurso de conforme Venturini (2009), que sustenta e ressignifica a palavra 'consumado'. Esse é um discurso que vem de outro lugar e se atravessa, como discurso transverso e ressoa porque significa para sujeitos, não só na atualidade, mas também no passado e, possivelmente, significará também no futuro.

Esse primeiro 'quadro', se é possível chamá-lo assim, fecha-se com as cinzas, também polissêmicas e instauradoras de redes parafrásticas, sinalizando para: limpe as cinzas e poderá ver que debaixo e além delas está a língua ou o movimento, como ressoa pela entrevista de João Guimarães Rosa, a Gunter Lorenz, em 1965, chamada de 'Diálogo com Guimarães Rosa', da qual foi retirada a citação que abre o quadro que faz progredir o documentário, enquanto textualidade.

No quadro seguinte, a rede parafrástica se constitui a partir das cinzas e se inicia com a citação: "O idioma é a única porta para o infinito, mas infelizmente está oculto sob montanhas de cinzas", de João Guimarães Rosa, referida anteriormente. O escritor diz que

[...] a linguagem e a vida são uma coisa só. Quem não fizer do idioma o espelho de sua personalidade não vive; e como a vida é uma corrente contínua, a linguagem também deve evoluir constantemente. Isto significa que, como escritor, devo me prestar contas de cada palavra e considerar cada palavra o tempo necessário até ela ser novamente vida ${ }^{7}$.

$\mathrm{Na}$ entrevista, o escritor sustenta que o dever de quem escreve é escrever (tratar da palavra e da língua) e na sequência da citação diz que o escritor tem o dever de limpar o idioma das cinzas. Trata-se de uma citação forte, de um posicionamento contundente e que faz rede com o que diz a voz dissonante, destacada em nosso texto, quando ela diz que a língua 'guardada', no museu é a língua da literatura, ressoando a entrevista de Guimarães Rosa, defendendo a língua como vida, em constante

${ }^{7}$ http://www.elfikurten.com.br/2015/12/joao-guimaraes-rosa-pensares-e-saberes.html, acesso em 09 de set. de 2017. 
movimento, cabendo ao escritor escrever, criar/recriar, inclusive a língua, legitimado pela poesia e pela licença poética.

Outro discurso que ressoa forte, não no discurso de Guimarães Rosa, mas na língua 'no museu' é o da preservação, a língua como patrimônio, que não pode ser 'contaminado' pelos problemas da sociedade e dos sujeitos. Pelo discurso que ressoa pela língua 'no museu' e pela citação de Guimarães Rosa, ressoam as 'igrejinhas', destacadas por Pêcheux (1997a, p. 56), em que cada um faz a sua própria leitura, instaurando espaços fechados, negando o discurso como percurso e, em relação à língua o movimento, as diferenças e a sua vocação para o não-um, como destaca Milner (1987).

O documentário segue com imagens do museu e, junto a elas, aparece um 'ruído', que se assemelha a um pesadelo, algo fora da realidade. Esse efeito é amenizado e ouve-se a voz e nela a afirmação de que as pessoas falam sem se preocupar com a língua, sem refletir sobre ela. Depois é a poesia e o destaque para a língua como som, barulho, murmúrio. Mais som e poesia. Uma voz que vem da poesia destaca que é impossível identificar o que é a língua, sendo ela tudo. Essa voz faz rede com a voz dissonante, segundo a qual "a língua não tem museu e não está no museu”, a língua que lá está não é a língua praticada, vivida, em movimento como percurso, conforme Gadet e Pêcheux (2004), Milner (1987) e Orlandi e pesquisadores que se inscrevem na Análise de Discurso, que têm a língua como objeto de estudo.

O quadro seguinte destaca-se pelo posicionamento em torno da 'Língua no Museu' e do 'Museu da Língua'. Trata-se de mais um fio na rede discursiva constituída no documentário, encaminhando para a mesma conclusão: o museu é institucional e prioriza a língua defendida pelos "imortais" da academia, por aqueles que negam o político e separam a literatura da vida. Retrocedendo um pouco, porque falamos de poesia, sublinhamos a 'voz' que fala do poema e do poema declamado, pelos quais ressoa a Literatura na vida e não fora dela. Com isso, constitui-se o efeito de que o que não está na vida, também não está na língua, de acordo com essa voz.

Fizemos dois recortes no documentário 'A chama da língua', o primeiro destaca a impossibilidade de colocar a língua no museu. Um que nega a língua no museu e outro que se contrapõe a essa negação e diz que língua está no museu e o que é o museu da Língua Portuguesa. 


\section{Recorte 01: A voz dissonante diz:}

É impossível colocar na língua no museu, porque a língua é algo em movimento, a língua é percurso. Pensar em colocar algo no museu, de alguma coisa que é da ordem do tradicional do museu, enquanto lugar de se guardar algo, que em princípio estaria estabilizado de sentidos. É impossível pensar o museu da língua.

Nesse recorte, a ênfase está na negação: É impossível colocar a língua no museu. É impossível pensar o museu da língua. Há também a definição de língua a partir de duas palavras-chaves: movimento e percurso. Essas duas palavras destacam o contraditório entre LÍNGUA e MUSEU. Da mesma forma que a língua foi caracterizada, o museu também foi e ele é considerado como o lugar de 'guardar' algo estabilizado de sentidos. Do que significou e significa sempre o mesmo. Trata-se da negação da língua no museu. O que está no museu pode ser ressignificado, mas não muda e a língua não é, segundo a voz dissonante, nada disso. Ela - a língua - está na ordem do que está sempre "se fazendo".

No segundo recorte, há a contra-identificação, pois o museu, até então, está em funcionamento e é da língua. Por isso, não há como dizer que o museu não é da língua, mas sim de dizer que língua constitui o museu e em que condições de produção ele funciona. Então o sujeito que se contra-identifica com a língua no museu assevera:

\section{Recorte 02: a língua que está no museu}

Muito embora o museu da língua esteja em outras condições de produção que não são condições que normalmente ou mais tradicional. Inclusive a política do museu seja mais instalações do que propriamente guardar uma língua. Muito embora, também, eles guardem uma língua, um momento, um modelo da língua literária.

Sublinhamos, nesse recorte, a resistência da língua no museu e o destaque para as condições de produção do museu da língua e para a política que emerge por meio do museu, sendo mais instalações do que o lugar que 'guarda' a língua. Apesar do distanciamento, esse museu 'guarda' uma língua, que é o modelo da 'língua literária', constituída muitas vezes como o modelo de Língua Portuguesa, identificando-se, portanto, com o nome da língua, ressoando as contradições e os antagonismos constitutivos do nome Língua Portuguesa.

O documentário não se encerra aí com os quadros apresentados e nem com os dois recortes. Outras 'vozes' se erguem e falam da língua e do museu, destacam o surgimento do museu e o questionamento em torno dele. Outras destacam a sua 
importância, mas todas as 'vozes' instauram uma rede que encaminha para uma conclusão: se há o museu da língua, a que está lá, não é a língua da vida, do movimento, do percurso. É a língua 'purificada', a do sonho, a da literatura, a da beleza, que apaga a incompletude, a divisão, o não-todo. Entendemos, enfim, que 'essas vozes' resistem à língua no museu e, a voz que chamamos de dissonante resume todas elas, organizandoas pelo enunciado 'a língua que nos une é a língua que nos diferencia', constituindo enfim uma rede e o documentário como um texto, tal como definido por Orlandi (2004), como peça de discurso.

\section{O Efeito de fechamento}

A pergunta que buscamos responder foi "Como a língua sempre em movimento e em transformação pode estar no museu e como se naturaliza e se legitima a língua no museu?" e a resposta para essa pergunta foi se fazendo na escritura do texto, na divisão do documentário em quadros, que não se fecharam, assim como esse texto, que também não fecha.

$\mathrm{Na}$ verdade, é preciso negar a língua em movimento e em transformação no museu. Elegemos uma voz, nomeando-a de dissonante, mas é necessário dizer, como já dissemos ao longo do texto, que essa voz se diferencia das demais porque ela sintetiza, organiza e diz que a língua que cabe no museu é um modelo de língua, não á língua', permeada por faltas, furos, equívocos. Os ruídos, os movimentos, o incêndio, as sirenes, a citação de Guimarães Rosa e mesmo a voz que destaca o fato de as pessoas não refletirem sobre a língua, instauram o efeito de sentido de negação da língua no museu. Essas vozes e o que 'dizem' sem dizer às imagens que estruturam o documentário sustentam as contradições e o posicionamento contrário à língua no museu e ao museu da língua.

Entendemos que trazer um fragmento da entrevista de João Guimarães Rosa instaura efeitos de sentidos contrários ao museu, sinalizando para os efeitos além do que está dito, tendo em vista que Rosa (1965) nega o político, mas na Literatura ele trabalha esse político, recria a língua, juntando pedaços que fazem sentido porque há um conhecimento de língua, mas há também a vida, o movimento, o percurso. Nada se fecha, ao contrário, abre possibilidades de interpretação. Isso porque assim como a língua, os textos também são incompletos e sempre deixam espaços e furos, nos quais cabem interpretações outras. 
O que estamos chamando de 'fechamento' é apenas um efeito, deixamos espaço para outras leituras do documentário e dizemos que a língua que está no museu uma modalidade de língua, grande parte dela vindo da Literatura, escolhida para ser 'a língua do museu e no museu' porque ela é aceita como a língua 'já feita', naturalizada porque é conhecida, mas nunca 'conformada' ou 'fechada'. Enfim, podemos dizer que o que está no museu, nega a língua como saturação, como um todo e, mais especificamente, que o documentário não seria uma materialidade significante se as 'vozes' que estão nele, não constituíssem redes e se um sujeito não às organizasse, mostrando que a língua não cabe no museu, por tudo que todos disseram.

\section{Referências bibliográficas}

BAUDRILlARD, J. Simulacros e simulação. Trad. Maria João da Costa Pereira. Lisboa: Ed. Relógio D’Água, 1991.

CATROGA, Fernando. O céu da memória: Cemitério Romântico e Culto Cívico dos Mortos em Portugal (1756-1911). Coimbra: Livraria Minerva Editora, 1999.

CATROGA, Fernando. Memória e História. In: PESAVENTO, Sandra Jatahy (Org.) . Porto Alegre: Ed. Da UFRGS, 2001.

CATROGA, Fernando. Memória, História e historiografia. Coimbra: Editora Quarteto, 2001a.

CATROGA, Fernando. Nação, mito, rito: Religião Civil e comemoracionismo (EUA, França, Portugal). Fortaleza: Edições NUDOC-UFC, Museu do Ceará, 2005.

CATROGA, Fernando. Os passos do homem como restolho do Tempo. Memória e fim do fim da História. Coimbra, Edições Almedina, 2009.

CERVO, Larissa Montagner. Língua Patrimônio Nosso. Tese de Doutorado sob a orientação de Amanda Scherer, pelo Programa de Pós-graduação em Letras, da UFSM, 2012.

COURTINE, Jean-Jacques. Analyse du discours politique (le discourse communiste adressé aux chrétiens). Langage, Paris, n. 62, juin, 1981.

DE CERTEAU, Michel. Invenção do cotidiano. Artes de fazer. Itrad. De Ephraim Ferreira Alves. Petrópolis/EJ: Vozes, 1994.

GADET, Françoise, PÊCHEUX, Michel. A língua inatingível: o discurso na história da Linguística. Trad. Bethânia Mariani e Maria Elizabeth Chaves de Mello. Campinas/SP: Pontes Editora, 2004.

GUIMARÃES, Eunice Pereira. Os documentários na constituição imaginária de sujeitos e identificações. Dissertação de Mestrado, sob a orientação de Maria Cleci Venturini, Programa de Pós-graduação em Letras, UNICENTRO, Guarapuava, 2013, 111 p.

MILNER, Jean-Claude. O amor da língua. Trad. Ângela Cristina Genuíno. Porto Alegre, Artes Médicas, 1987. 
NORA, Pierre. Entre mémoire et historie. La problématique des lieux. In Les lieux de mémoire, Paris: Gallimard, 1984, v. I.

ORLANDI, Eni. Análise de discurso: princípios e procedimentos. Campinas: Pontes, 1999.

ORLANDI, Eni. Língua e conhecimento linguístico. São Paulo: Cortez, 2002.

ORLANDI, Eni. Interpretação: autoria, leitura e efeitos do trabalho simbólico. Campinas, SP: Pontes, 2004.

ORLANDI, Eni. Documentário: acontecimento discursivo, memória e interpretação. In Leituras do Político. ZANDWAIS Ana [e] ROMÃO, Lucília Maria Souza. Porto Alegre: Editora da UFRGS, 2011.

ORLANDI, Eni. Gestos de leitura. Da história no discurso. Homenagem a Denise Maldidier. 2 ed. Campinas, SP: Editora da Unicamp, 2014.

ORLANDI, Eni. Eu, tu, ele - discurso e real da História. Campinas/SP: Pontes Editores, 2017.

PÊCHEUX, Michel. Semântica e discurso: uma crítica à afirmação do óbvio. Campinas/SP: Editora da UNICAMP. 1997.

PÊCHEUX, Michel. Ler o arquivo hoje. In: ORLANDI, Eni (Org.). et al. Gestos de leitura. Da história no discurso. Homenagem a Denise Maldidier. 2. ed. Campinas, SP:Editora da Unicamp, 1997a.

PÊCHEUX, Michel. $O$ discurso: estrutura ou acontecimento. Trad. De Eni Orlandi. 3 ed. Campinas, SP: Pontes, 2002.

SILVA SOBRINHO, José Simão. A língua que nos une: língua, sujeito e Estado no museu da Língua Portuguesa. Tese de doutorado sob a orientação de Eni Orlandi, Campinas, IEL, 2011.

SOUSA, Lucília Maria. Exposição do Museu de Língua Portuguesa: arquivo e acopntecimento e(m) discurso. São Carlos: Pedro \& João Editores, 2011.

VENTURINI, Maria Cleci. Imaginário urbano: espaço de rememoração/comemoração. 1a.ed. Passo Fundo: UPF Editora, 2009.

VENTURINI, Maria Cleci Museus e espaços públicos no encontro/desencontro da m,emória histórica e do corpo-memória/corpo documento. In VENTURINI, Maria Cleci Museus, arquivos e produção do conhecimento em (dis)curso. Campinas, SP: Pontes Editores, 2017. 


\section{Revista do Laboratório de}

Estudos Urbanos do Núcleo

de Desenvolvimento da Criatividade

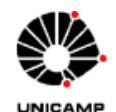

\section{Para citar essa obra:}

VENTURINI, Maria Cleci, SCHON, Suhaila Mehanman. Documentário, língua e o museo no/pelo olhar discursivo. In: RUA [online]. Volume 24, número 2 - p. 543-560 - e-ISSN 2179-9911 novembro/2018. Consultada no Portal Labeurb - Revista do Laboratório de Estudos Urbanos do Núcleo de Desenvolvimento da Criatividade.

http://www.labeurb.unicamp.br/rua/

Capa: CORPO DE BOMBEIROS DE SP. Museu da Língua Portuguesa em 21/12/2015. Disponível em: https://brasil.elpais.com/brasil/2016/02/26/politica/1456513671_515845.html

\section{Laboratório de Estudos Urbanos - LABEURB}

Núcleo de Desenvolvimento da Criatividade - NUDECRI

Universidade Estadual de Campinas - UNICAMP

http://www.labeurb.unicamp.br/

Endereço:

LABEURB - LABORATÓRIO DE ESTUDOS URBANOS

UNICAMP/COCEN / NUDECRI

CAIXA POSTAL 6166

Campinas/SP - Brasil

CEP 13083-892

Fone/ Fax: (19) 3521-7900

Contato: http://www.labeurb.unicamp.br/contato 